\title{
The 'whole-animal approach' as a heuristic principle in neuroscience research
}

\author{
ALEJANDRO SERANI-MERLO ${ }^{1}$, RODRIGO PAZ $^{2,3}$ and ANDRÉS CASTILLO ${ }^{1}$
}

1. Facultad de Medicina, Universidad de los Andes, Chile. 2. Instituto Psiquiátrico Dr. José Horwitz Barak, Chile. 3. Department of Neurosciences, University of New Mexico School of Medicine, USA.

\begin{abstract}
Neuroscience embraces a heterogeneous group of disciplines. A conceptual framework that allows a better articulation of these different theoretical and experimental perspectives is needed. A 'whole-animal approach' is proposed as a theoretical and hermeneutic tool. To illustrate the potential of this point of view, an overview of the research that has been performed in the extinction of fear-conditioned responses from Pavlov to the present is discussed. This is an example of how a whole-animal-based approach may help to organize and integrate basic and clinical neuroscience research. Our proposal is in agreement with recent statements calling for more integrative approaches in biological and neuropsychiatric research.
\end{abstract}

Key terms: epistemology, neurophilosophy, fear conditioning, extinction, reductionism.

\section{INTRODUCTION}

The term neuroscience encompasses a wide array of disciplines that, at first glance, only seem to have in common the study of the nervous system and its parts. Neuroanatomy, biophysics, molecular and cellular neurobiology, neurochemistry, electrophysiology, behavioral neuroscience, neuropsychology, neuropsychiatry, neuronal networks, and artificial intelligence, as well as neurophilosophy, are some of the multiple stances taken. These disciplines not only differ in the different aspects of the nervous system that they scrutinize, but also in the epistemological perspective that they assume and the theoretical or practical finality that they pursue. In this scenario, it seems reasonable to ask whether it is possible to attain a unitary view of all these different perspectives that is not just an arbitrary convention, and to what extent this unitary view might increase our understanding of the nature of the nervous system. This essay revolves around these two questions.

\section{ORGAN OR SYSTEM?}

The concept "organ" points to a concrete reality. Conversely, the concept "system" envisages the underlying hypothesized interactions among organs and parts. Both concepts depend on the notion of function. When the term "organ" is used in order to discuss the functioning parts of living organisms, the manifold relationships that each organic part of the organism establishes with each other usually are overlooked. On the other hand, the term "system" - when it is applied to nervous structures- refers to a kind of totality that is not equivalent to the total organism to which the system belongs. If this distinction is not appropriately considered, the conceptualization of brain and nerves as a system may lead to the perception of these structures and their relationships as a whole locked in itself (15). 
In their book, De máquinas y seres vivos (0n Machines and Living Beings), Maturana and Varela state that functional considerations are arbitrary attributions made by the observer (11). In their view, only the self-maintaining or "autopoietic" organization of processes can define living beings (23). This also applies to the nervous system in which its autopoietic organization of processes is the only function that can be the object of scientific study. Thus, in this doctrine the nervous system is conceptualized as a closed system, which does not have direct access to "external reality" (19). Conversely, general biology and physiology historically have been in agreement with the primacy of functional considerations at the moment of analyzing living beings. From this stance, biological functions are not considered arbitrary attributions made by the observer, but real dynamic relationships between parts of the organism. These dynamic relationships can be inferred from the observation of living beings, their parts, actions and behavior. As noted long ago by Aristotle, animal functions can be recognized properly only from the whole-animal perspective. Thus, the processing of information in the visual cortex would be a sub-function of the more global function of sight, in which the proper agent is the whole animal. Likewise, arterial chemoreception constitutes a subfunction of the cardio-respiratory system and the autonomic nervous system, whose function is, in turn, subordinated to the homeostatic adaptations of the whole animal. In consequence, primary and real biological functions are, from this perspective, only those tasks in which the living organism is involved as a whole.

WHAT IS THE FUNCTION OF BRAIN, SPINAL CORD, NERVES, AND MUSCLES?

It is possible to conceptualize the diversity of nervous functions in three fundamental tasks that can be ordered hierarchically as follows: 1) the autopoietic function of selfbuilding or of self-maintenance, which is common to all structures of the organism; 2 ) the integrative and modulating function mediated by the sympathetic, parasympathetic and neuro-endocrine subsystems (autonomic nervous system); and 3 ) the function of establishing a relationship between the animal and its environment, which sub serves general and specific patterns of behavior. In this trilogy, the first two functions, i.e., the autopoietic and integrative, are required for performing the relational function. At the same time, the relation function subordinates the other functions in the generation of complex behavioral patterns. Regarding the relational or behavioral function, three basic aspects can be distinguished, all of which are intimately bonded and operate simultaneously: 1) directional, 2) motivational, and 3) executive $(7,16)$. For each aspect of behavior, it is possible to recognize a particular sub-group of organic structures that are activated preferentially by these different aspects of animal behavior. First of all, by using its sensory organs and corresponding centers of information reception and processing in the brain, the animal notices that something is changing in its environment. This first aspect can be conceptualized as the cognitive subfunction of behavior. Simultaneously, emotional memories and/or instinctive patterns of behavior associated with the stimulus by experience or instinct activate aversive or appetitive responses in the animal. This stage corresponds to the affective sub-function of behavior, which is essential for the triggering, persistence and ending of complex behaviors. Some of the brain structures that are recruited by emotion-arousing stimuli include: the ventromedial and orbitofrontal cortex; the anterior cingulate; the amygdaloid complex; the nucleus accumbens; the bed nucleus of the stria terminalis; and an array of diencephalic, mesencephalic and brain stem nuclei, whose main feature is the release of neuromodulators dopamine, noradrenaline, acetyl choline, and serotonin, which, in turn, play critical roles as regulators of the salience and emotional intensity of the experience. Finally, and in close dependence on the synergic cognitive-affective operation, the 
executive sub-function takes shape in motor centers and their peripheral nervous pathways, whose final effectors are the striated muscle fibers.

From the preceding considerations, an organizational principle for the multiple aspects covered by research in neuroscience may emerge. This organization stems from the recognition of the different functions that nervous structures play in animal behavior. Thus, it is proposed that the presence of this organization may provide a heuristic guide for understanding the nervous system, designing experiments, and interpreting their results. From this point of view, it is interesting to examine the manner in which some classic neurophysiology textbooks organize the study of the nervous system. Comparing two texts from the $1970 \mathrm{~s}$, the $20^{\text {th }}$ edition of Howell-Fulton Physiology and Biophysics by Ruch and Patton (22) and the $13^{\text {th }}$ edition of Medical Physiology by Vernon Mountcastle (13), the cognitive function would be represented by somatic sensation, sensory systems, memory, and superior brain functions. The executive function would be represented by a cluster constituted by central and peripheral control of movement and posture and the study of skeletal muscles. The emotional function, on the other hand, is not as clearly treated as the others. In Ruch-Patton's work, a whole chapter "Neurophysiology of the Emotions, Affections and Behavior Specific to the Species" stands out, and these aspects are entirely omitted in the text of Mountcastle. In contrast, in the third edition of Eric Kandel's textbook, Principles of Neural Science, a "behaviorcentered approach" is proposed as an organizer of the study of neuroscience, even though, as in Maturana and Varela's book, the system - or even the organ itself, in this case - also is made equivalent with the animal, as expressed in the sentence: "what we commonly call mind is a range of functions carried out by the brain" (Part I, Ch.1) (8). From our perspective, mental functions only can be carried out by the animal as a whole, by means of its parts; from which, the nervous system is particularly important for the generation of most of the biological functions that are necessary for the existence of mental processes.

RESEARCH IN THE EXTINCTION OF FEARCONDITIONED RESPONSES

To better illustrate the hermeneutic potential of a whole-animal perspective, we shall briefly expose some problems that appear in the research area focused on the extinction of fear-conditioned responses (1). This line of research has its origins in Pavlov's seminal observations about the emergence of conditioned reflexes associated with fear-arousing experiences. In these experiments, fear responses are evoked in animals by applying painful aversive stimuli to their bodies (the unconditional stimulus), at the same time that a previously neutral stimulus, for example the ring of a bell (the conditional stimulus), is temporally coupled to the noxious experience. In this way, the neutral stimulus now acquires the capacity to induce fear responses (conditioned response) in the absence of the noxious stimulus. In other words, the animal learns that under these particular circumstances also known as the context of learning - a stimulus that previously had no meaning becomes a strong predictor of pain and danger. Under these experimental conditions, Pavlov also observed that the continuous presentation of the conditional stimulus, in this case the sound of the bell, to the animal in the absence of noxious stimulation led gradually to the disappearance of the conditioned response, or in other words, the bell's ring lost its capacity to evoke fear responses in the animal in this new context. Pavlov initially called the disappearance of the conditioned response "extinction" of the response; others have conceptualized it as an "unlearning" process. Later on, Pavlov came to realize the inadequacy of this conceptualization of this phenomenon, when he noticed that, after some variable time, the conditioned response could reappear spontaneously or the association could be re-acquired after shorter trials of 
reconditioning, suggesting that the previously learned association was not erased from the animal memory but somehow persists in such a way that the association did not have to be re-learned as it was the first time (17). Based upon these intriguing observations, Pavlov reconceptualized the abolition phenomenon in terms of "inhibition," indicating that the learned association was not erased by the extinction trial but, in fact, persists as a memory that later on can be re-activated. For a long time, the concepts extinction and unlearning, as the complete erasing of the fear-associated learning, were maintained by basic and clinical neuroscience researchers, without considering the later rectifications introduced by Pavlov. In fact, it was not until the identification of post-traumatic stress disorder (PTSD) as a disabling mental disorder, which may appear months or even years after the occurrence of the traumatic experience in some people exposed to severe life-threatening trauma, that the interest in these late Pavlovian concepts was renewed (24). Moreover, some influential clinical investigators in the PTSD field now are proposing that underlying the pathological behavior of people affected with PTSD, a constitutional incapacity to "extinguish," "unlearn" or "inhibit" fear-conditioned responses might be found (3).

In order to test this hypothesis, extensive research is being carried out to determine the molecular $(10,25)$, cellular (6), and anatomical (12) basis of the capacity for inhibiting fear-conditioned responses in animals and humans (20). Likewise, animal models of deficient capacity for consolidating memories of fearextinguished responses are being assayed -in experiments that are ethically and technically impracticable in human subjects- in a manner that may shed light on the potential causes of these defects in clinical populations (18). From the psychological point of view, the importance of understanding the context in which conditioning takes place, as well as the role of new learning experiences in diminishing the intensity and frequency of the re- emergence of inhibited conditioned fears, also have been stressed recently (14).

Overall, we believe that the development of this particular research field is an interesting example of how observations about whole-animal behavior can be approached from an anatomical, electrophysiological, molecular, genetic, and more recently, a pharmacological (4, 21) and clinical point of view, in such a way that both reductionistic and more holistic approaches can contribute to unraveling the causes of complex behavioral phenomena. How has this been possible? It appears clear to us that Pavlov's interests, while ample, were centered mostly around the executive dimension of behavior, namely on the observable or measurable effects of the manipulations performed. Psychologists and psychiatrists have become interested in the effects that the recovery of inhibited acquired fears has on people's conscious and unconscious affective lives. Molecular neurobiologists and geneticists have undertaken the study of the modifications or faults in the structure of the brain. Albeit exciting, it is noteworthy that with the exception of Pavlov, other researchers have not addressed the question about what exactly the fact of being conditioned to the sound of a bell means for the whole animal. The cognitive-affective-executive behavioral system of the animal is adapted, in principle, to function in a natural environment devoid of bell-rings. What advantage does it represent for animals that their affective and executive responses are conditioned? Ethology has taught us how fixed and species-specific the instinctive patterns of reaction and conducts in animals are. These unlearned stereotyped patterns of behavioral responses allow the animal to act without the need of learning or deliberation. In this way, a great efficacy and quickness is provided for animal actions. However, this evolutionary advantage simultaneously imposes important constraints on animal behavior. Because instinctive patterns of behavior are by definition stereotyped and automatic, animals easily could be trapped by these rigid patterns of conduct in such a 
way that would not allow the emergence of more adaptive behavior. From this perspective, it is likely that in a stable environment with seasonal changes, the conditioning of reactions and conducts permits a finer tuning of its responses to changing stimuli (i.e., the sounds of walking over leaves in fall, snow in winter, sand in summer). Therefore, the inhibition of conditioned responses and not their extinction appear as a highly adaptive biological mechanism that allows the animal's instinctive patterns of conduct to express a range of plasticity and adaptability to the context that otherwise would have been unobtainable.

\section{COROLLARY}

The emergence of molecular biology and genetics in biology research during the 1970s through 1980s brought a fresh approach to biological thinking. The idea that complex phenomena finally would be explained by the identification and characterization of the molecules involved in these processes was appealing. However, this reductionistic approach is not enough to understand and predict the behavior of complex systems $(5,9,27)$. In the field of neuroscience, this awareness is encouraging the development of more integrative lines of research, which are illuminating areas that it would have been impossible to explore in the past with a "naively reductionistic" approach $(2,26)$. The development in our clinical and scientific community of more integrative research is a challenging endeavor.

\section{ACKNOWLEDGMENTS}

This research was financed partly by a research grant from Dirección de Investigación Universidad de los Andes, Santiago, Chile (FAI MED-002-05) to ASM and $\mathrm{AC}$, and by a research grant to RP, from the Ministerio de Planificación y Cooperación (MIDEPLAN), Gobierno de Chile, Beca Presidente de la República, Chile.

\section{REFERENCES}

1. BOUTON ME (2002) Context, ambiguity, and unlearning: Sources of relapse after behavioral extinction. Biol Psychiatry 52: 976-986

2. CASPI A, SUGDEN K, MOFFIT TE, TAYLOR A, CRAIGIW, HARRINGTON H, MCCLAY J, MILL J, MARTIN J, BRAITWITE A, POULTON R (2003) Influence of life stress on depression: Moderation by a polymorphism in the 5-HTT gene. Science 301: 386389

3. CHARNEY DS (2004) Psychobiological mechanisms of resilience and vulnerability: Implications for successful adaptation to extreme stress Am J Psychiatry 161: 195-216

4. CHATWAL JP, DAVIS M, MAGUSCHAK KA, RESSLER KJ (2005) Enhancing cannabinoid neurotransmission augments the extinction of conditioned fear. Neuropsychopharmacology 30: 516524

5. GABBARD GO (2005) Mind, brain, and personality disorders. Am J Psychiatry 162: 648-55

6. HUMEAU Y, HERRY C, KEMPT N, SHABAN H, FOURCARDOT E, BISSIERE S, LUTHI A (2005) Dendritic spine heterogeneity determines afferentspecific Hebbian plasticity in the amygdala. Neuron 45: 119-131

7. JONAS H (1966) The phenomenon of life, toward a philosophical biology. Chicago/London: The University of Chicago Press. pp: 99-107.

8. KANDEL ER, SCHWARTZ JH, JESSELL TM (1991) Principles of Neural Science. 3rd ed., New York: Elsevier

9. KENDLER KS (2005) Toward a philosophical structure for psychiatry. Am J Psychiatry 162: 433-440

10. MARSICANO G, WOTJAK CT, AZAD SC, BISOGNO T, RAMMES G, CASCIO MG, HERMANN H, TANG J, HOFMANN C, ZIEGLGANSBERGER W, DI MARZO V, LUTZ B (2002) The endogenous cannabinoid system controls extinction of aversive memories. Nature 418: 530-534

11. MATURANA H VARELA F (1972) De máquinas y seres vivos. Santiago de Chile: Editorial Universitaria

12. MILAD MR, QUIRK GJ (2002) Neurons in medial prefrontal cortex signal memory for fear extinction. Nature 420: 70-74

13. MOUNTCASTLE V (1974) Medical Physiology I. Saint Louis: Mosby

14. MYERS KM, DAVIS M (2002) Behavioral and neural analysis of extinction. Neuron 36: 567-584

15 PALACIOS AG, BACIGALUPO J (2003) Francisco Varela (1946-2001): Filling the mind-brain gap: A life adventure. Biol Res 36: 9-12

16 PALACIOS AG, BOZINOVIC F (2003) An "enactive" approach to integrative and comparative biology: Thoughts on the table. Biol Res 36: 101-105

17. PAVLOV IP (1927) Conditioned Reflexes. Oxford, UK: Oxford University Press

18. PAZ R, CALDEIRA J, ALLAN A, CALDWELL K (2005) "Deficits in consolidation but not acquisition of the extinction of fear conditioned responses in FAE mice suggest that medial frontal cortex is impaired in these animals" International Extinction Conference. Puerto Rico

19. PETITOT J (2003) Morphodynamical enaction: The case of color. Biol Res 36: 107-112

20. PEZAWAS L, MEYER-LINDENBERG A, DRABANT EM, VERSCHINSKI BA, MUNOZ KE, KOLACHANA BS, EGAN MF, MATTAY VS, HARIRI AR, WEINBERGER DR (2005) 5-HTTLPR 
polymorphism impacts human cingulate-amygdala interactions: A genetic susceptibility mechanism for depression. Nat Neurosci 8: 828-34

21. RESSLER KJ, ROTHBAUM BO, TANNENBAUM L, ANDERSON P, GRAAP K, ZIMAND E, HODGES L, DAVIS M (2004) Cognitive enhancers as adjuncts to psychotherapy: Use of D-cycloserine in phobic individuals to facilitate extinction of fear. Arch Gen Psychiatry 6: 1136-1144

22. RUCH TH, PATTON H D (1979) Howell-Fulton Physiology and Biophysics I, The Brain and neural function. Philadelphia/London/Toronto: W B Saunders

23. RUDRAUF D, LUTZ A, COSMELLI D, LACCHAUX J-Ph, LE VAN QUYEN M (2003) From autopoiesis to neurophenomenology: Francisco Varela's exploration of the biophysics of being. Biol Res 36: 27-65

24. SHALEV AY, FREEDMAN S, PERIT, BRANDES D, SAHAR T, ORR SP, PITMAN RK (1998) Prospective study of posttraumatic stress disorder and depression following trauma. Am J Psychiatry 155: 630-637

25. SHUMYATSKY GP, TSYVETKOV E, MALLERET G, VRONSKAYA S, HATTON M, HAMPTON L, BATTEY JF, DULAC C, KANDEL ER, BOLSHAKOV VY (2002) Identification of a signaling network in lateral nucleus of amygdala important for inhibiting memory specifically related to learned fear. Cell 111: 905-918

26. SPANAEL R, PENDYALA G, ABARCA C, ZGHOUL $\mathrm{T}$, SANCHIS-SEGURA $\mathrm{C}$, MAGNONE MC, LASCORZ J, DEPNER M, HOLZBERG D, SOYKA M, SCHREIBER S, MATSUDA F, LATHROP M, SCHUMAN G, ALBRECHT (2005) The clock gene Per2 influences the glutamatergic system and modulates alcohol consumption. Nat Med 11: 35-42

27. STRANGE K (2005) The end of "naive reductionism": Rise of systems biology or renaissance of physiology? Am J Physiol Cell Physiol 288: C968-974 